\title{
A REVIEW OF THE ANXIOLYTIC EFFECT OF MUSIC AND ITS CLINICAL APPLICATIONS Dr. Sivaprakash B *
}

\section{Introduction}

Neuroscience has established beyond doubt that the mind is a product of the brain. It is also known that the central and peripheral nervous systems extend their cells and synapses throughout the body. ${ }^{1}$ The mind exerts a profound influence on physical health through intricate and widespread neuro-endocrine and neuro-immune pathways. Mental health is a key determinant of overall health. Anxious and depressed moods, for example, initiate a cascade of adverse changes in endocrine and immune functioning, and create increased susceptibility to physical illnesses. ${ }^{2}$ The field of psychosomatic medicine emphasizes the unity of mind and body and the significance of psychological factors in all disease states. ${ }^{3}$ Concepts derived from psychosomatic medicine influenced the emergence of complementary and alternative medicine $(\mathrm{CAM}){ }^{3}$

CAM refers to the various disease-treating or disease-preventing practices whose methods and efficacy differ from traditional or conventional biomedical treatment. ${ }^{4}$ Some of these approaches can be and are used in conjunction with traditional/allopathic medicine. ${ }^{4}$ According to the National Center for Complementary and Alternative Medicine, USA, CAM is a group of diverse medical and health care systems, practices, and products that are not generally considered to be part of conventional medicine. Mind-body medicine is a domain within CAM that focuses on the interactions among the brain, mind, body, and behavior, and the powerful ways in which emotional, spiritual, and behavioural factors can directly affect health. Mind-body interventions include music therapy, yoga, meditation, biofeedback etc. ${ }^{4}$ Music therapy is the clinical and evidence-based use of music interventions to accomplish individualized goals within a therapeutic relationship. ${ }^{5}$ Music therapy has been shown to be an efficacious and valid adjunctive treatment option for patients with a variety of diagnoses. ${ }^{5}$
Bradt and Dileo ${ }^{6}$ have explained the concepts of music medicine and music therapy. Interventions are categorized as music medicine when passive listening to pre-recorded music is offered by medical personnel. In contrast, music therapy requires the implementation of a music intervention by a trained music therapist, the presence of a therapeutic process, and the use of personally tailored music experiences. These music experiences include listening to live, improvised or pre-recorded music, performing music on an instrument etc. Music therapy provides opportunities for anxiety and stress reduction, non-pharmacological management of pain and discomfort, and positive changes in mood and emotional states. ${ }^{5}$

Systematic research on the effects of music and music therapy on patients has burgeoned during the past 20 years. A substantial body of literature exists to support the effectiveness of music therapy. In a recent review, $\mathrm{Lake}^{7}$ notes that anxious adult patients randomly assigned to music-assisted reframing experienced greater reductions in overall anxiety than patients who received conventional cognitive therapy. Frequent listening to music probably has beneficial effects on endorphins and other neurotransmitters that mediate improvements in depressed $\operatorname{mood}^{7}$. Music alone or in combination with guided imagery improves mood in depressed cancer patients ${ }^{7}$. Depressed outpatients reported significant improvements in mood and beneficial changes in heart rate and blood pressure soon after listening to tranquil music ${ }^{7}$. Regular singing, engaging in dance therapy, listening to music, and participating in musical games improve cognitive and behavioural functioning in individuals with severe dementia, who experience reduced agitation, reduced wandering, enhanced social interaction, improved mood, reduced irritability or fear, and increased cooperative behavior ${ }^{7}$. Calming background music significantly reduces irritable behavior, anxiety, and depressed mood in nursing home patients with dementia ${ }^{7}$. 
Music therapy can help to relieve pain and reduce stress and anxiety for the patient, resulting in improved respiration, lower blood pressure, improved cardiac output, reduced heart rate, relaxed muscle tension. ${ }^{5}$ Music therapy has been shown to have a significant effect on a patient's perceived effectiveness of treatment, self-reports of pain reduction, relaxation, respiration rate, anxiety levels, and amount of analgesic medication. ${ }^{5}$

There are a number of individual factors that influence responses to music. These include age, gender, cognitive function, severity of stress, anxiety, discomfort and pain, training in music, familiarity with and reference for the music, culture, and personal associations with the music. ${ }^{6}$ The response of patients/subjects to music therapy is thus highly subjective. Published Indian research literature on music therapy appears to be meagre and elusive. Given the promising results of music therapy research performed in other countries and the fact that culture and socioeconomic factors significantly influence response to music therapy, it may be worthwhile for the scientific community of our nation to start building a repository of indigenous research on music therapy.

Research reports on the impact of music on normal human physiological processes in healthy individuals are not as abundant as research data on the therapeutic effects on music in the context of human illness. It stands to reason that the precise nature of the physiological impact of music needs to be elucidated in through systematic research on healthy subjects, before music can be routinely prescribed with confidence in the clinical setting. In addition, rigorous randomized controlled trials involving the exposure of healthy subjects to music will help to clarify and establish the role of music in disease prevention, health promotion, and positive psychology. Existing research data pertaining to these issues needs to be replicated in the Indian context, for reasons mentioned earlier.

This review starts with a brief overview of fundamental physiological correlates relevant to the theme of this study, including the neurobiology of anxiety. Salient aspects of the autonomic nervous system are discussed, followed by the relationship between anxiety and the autonomic nervous system. The physiological impact of anxiety on the cardiovascular and respiratory systems is reviewed, in brief. Recent research findings pertaining to the neurophysiology of music are highlighted. A brief sketch of the physiological effect of music on healthy subjects is provided, followed by an elaborate review of research on the anxiolytic effect of music in diverse clinical scenarios. Health implications of anxiety, elevated heart rate and blood pressure are discussed briefly. The review ends with an emphasis on the need for further research on the impact of music on human physiology.

\section{Overview of basic physiological correlates}

\section{Neurobiology of anxiety}

Anxiety is a reaction to stress that has both psychological and physical features. The feeling is thought to arise in the limbic system, a brain region that governs many intense emotional responses. The prevailing neurocircuitry models of anxiety disorders emphasize interactions among limbic structures, especially the amygdala, hippocampus, hypothalamus, and periaqueductal gray, and cortical regions within the sensory association areas and the medial and orbital portions of the prefrontal cortex. ${ }^{8}$

\section{Autonomic nervous system}

It is well known that the hypothalamus is a crucial component of the neural circuitry regulating not only emotions, but also autonomic, endocrine and some somatic functions. ${ }^{9}$ The limbic system integrates the highly processed sensory and cognitive information content of the cerebral cortical circuitry with the hypothalamic pathways that control autonomic and endocrine systems. ${ }^{9}$ Stimulation of the lateral nucleus of the hypothalamus via afferent projections from the central nucleus of the amygdala, bed nucleus of the stria terminalis, or ventral striatum activates the sympathetic nervous system, producing increases in blood pressure and heart rate, sweating, piloerection, and pupillary dilation. ${ }^{8}$ During stress, the secretion of $\mathrm{CRH}$ from the PVN of the hypothalamus increases peripheral ACTH levels, which stimulates the adrenal glands to secrete cortisol. ${ }^{8}$ 


\section{Emotions, autonomic nervous system and the cardiovascular system}

Autonomic nervous system activity is viewed as a major component of the emotion response in many recent theories of emotion. ${ }^{10}$ Anxiety is characterized by sympathetic activation and vagal deactivation, a pattern of reciprocal inhibition. ${ }^{10}$ Peripheral manifestations of anxiety include hypertension and tachycardia. ${ }^{11}$ The autonomic nervous system of some patients with anxiety disorder exhibit increased sympathetic tone. ${ }^{11}$ There are descending tracts to the medullary vasomotor area from the cerebral cortex (particularly the limbic cortex) that relay in the hypothalamus. These fibres are responsible for the blood pressure rise and tachycardia produced by emotions such as sexual excitement and anger. ${ }^{12}$

\section{Anxiety and the respiratory system}

One common symptom associated with anxiety is hyperventilation. Abnormal respiratory behavior has been identified in anxiety disorders, particularly panic disorder. ${ }^{13}$ Dyspnoea can coexist with anxiety. ${ }^{14}$ Anxiety is often a component of dyspnoea experienced by patients with chronic respiratory illness. ${ }^{14}$

\section{Neurophysiology of music}

Music is capable of evoking exceptionally strong emotions and of reliably affecting the mood of individuals. ${ }^{15}$ Koelsch $^{16}$ reviewed the functional imaging studies conducted on the investigation of emotion with music. These studies showed involvement of limbic and paralimbic cerebral structures (such as amygdala, hippocampus, parahippocampal gyrus, temporal poles, insula, ventral striatum, orbitofrontal, as well as cingulate cortex) during the processing of music with emotional valence (such as pleasant or unpleasant). These studies imply that musicevoked emotions can modulate activity in virtually all limbic and paralimbic brain structures. These structures are crucially involved in the initiation, generation, detection, maintenance, regulation and termination of emotions that have survival value for the individual and the species.
Menon and Levitin ${ }^{17}$ used functional magnetic resonance imaging and functional/effective connectivity analyses to show that listening to music strongly modulates activity in a network of mesolimbic structures involved in reward processing including the nucleus accumbens (NAc) and the ventral tegmental area (VTA), as well as the hypothalamus and insula, which are thought to be involved in regulating autonomic and physiological responses to rewarding and emotional stimuli. Responses in the NAc and the VTA were strongly correlated pointing to an association between dopamine release and NAc response to music. Responses in the NAc and the hypothalamus were also strongly correlated across subjects, suggesting a mechanism by which listening to pleasant music evokes physiological reactions. Findings showed significant VTA-mediated interaction of the NAc with the hypothalamus, insula, and orbitofrontal cortex.

\section{Physiological effect of music on healthy subjects}

Knight and Rickard ${ }^{18}$ demonstrated that relaxing music prevents stress-induced increases in subjective anxiety, systolic blood pressure, and heart rate in healthy subjects. Undergraduate students were exposed to a cognitive stressor task involving preparation for an oral presentation either in the presence of music, or in silence. Measures of subjective anxiety, heart rate, blood pressure, cortisol, and salivary IgA were obtained during rest and after presentation of the stressor. The stressor caused significant increases in subjective anxiety, heart rate, and systolic blood pressure in male and female controls. These stress-induced increases were each prevented by exposure to music. Music also enhanced baseline salivary IgA levels in the absence of any stress-induced effects. These findings provide experimental support for claims that music is an effective anxiolytic treatment.Miller et $\mathrm{al}^{19}$ evaluated the extent to which music may affect endothelial function. Endothelial function was assessed by brachial artery flow-mediated dilation (FMD). Self-selected joyful music was associated with increased FMD to a magnitude previously observed with aerobic activity or statin therapy. The authors concluded that listening to joyful music may be an adjunctive life-style intervention for the promotion of vascular health. 


\section{Anxiolytic effect of music in clinical scenarios}

\section{Coronary heart disease}

White ${ }^{20}$ examined the effects of relaxing music on elevated state anxiety in patients with a confirmed medical diagnosis of acute myocardial infarction. Statistically significant reduction in heart rate, respiratory rate, and state anxiety scores were found in the group that listened to relaxing music. Elliott ${ }^{21}$ conducted a randomized, controlled trial to test the efficacy of music and muscle relaxation techniques in reducing the anxiety of patients admitted to a coronary care unit with unstable angina pectoris or acute myocardial infarction. No significant reductions in anxiety were achieved for patients using music or muscle relaxation interventions when compared with the control group. Barnason ${ }^{22}$ studied the effects of music interventions on anxiety in the patient after coronary artery bypass grafting. No significant differences were reported for anxiety ratings. There were significant effects over time for heart rate and systolic and diastolic blood pressure, which indicated a generalized physiologic relaxation response.

A recent Cochrane review ${ }^{6}$ concluded that music listening may have a beneficial effect on blood pressure, heart rate, respiratory rate, anxiety, and pain in persons with coronary heart disease. This review stated that that the quality of the evidence is not strong and the clinical significance unclear.

\section{Perioperative scenarios}

Several researchers have studied the role of music in the control of patients' anxiety in perioperative scenarios. Music can reduce the anxiety and stress of patients in the surgical holding area. ${ }^{23}$ Augustin and Hains ${ }^{24}$ demonstrated that music can be more beneficial than preoperative instruction alone in reducing ambulatory surgery patients' preoperative anxiety. Patients who listened to their choice of music before surgery in addition to receiving preoperative instruction had significantly lower heart rates than patients in the control group who received only preoperative instruction. Differences in experimental and control group patients' blood pressure measurements and respiratory rates approached significance. In a controlled study ${ }^{25}$, it was observed that music produced a significant reduction in anxiety and respiratory rates of women awaiting breast biopsy. Wang et $\mathrm{al}^{26}$ evaluated the role of music in the management of preoperative anxiety through a randomized, controlled study. Patients who listened to music before surgery reported lower levels of state anxiety. Physiological outcomes (electrodermal activity, blood pressure, heart rate, cortisol, and catecholamine data) did not differ, however, between the study groups. A recent randomized controlled trial ${ }^{27}$ demonstrated that exposure to music resulted in a statistically significant reduction of preoperative anxiety in patients undergoing day surgery.

Patients who listened to their choice of music during surgery with local anaesthesia experience significantly lower anxiety levels, heart rates, and blood pressure than patients who did not listen to music. ${ }^{28}$ Allred et a ${ }^{129}$ studied the effect of music on postoperative pain and anxiety following total knee arthroplasty. The music group's decrease in pain and anxiety was not significantly different from the comparison rest group's decrease in pain or anxiety. However, statistical findings within groups indicated that the sample had a statistically significant decrease in pain and anxiety over time. In a systematic review of 42 randomized controlled trials of the effects of music interventions in perioperative settings $\mathrm{s}^{30}$, it was observed that music intervention had positive effects on reducing patients' anxiety and pain in approximately half of the reviewed studies. The authors of this review stated that further research into music therapy is warranted in light of the low cost of implementation and the potential ability of music to reduce perioperative patient distress.

\section{Ventilatory assistance}

Chlan $^{31}$ noted that a single music therapy session was found to be effective for decreasing anxiety and promoting relaxation, as indicated by decreases in heart rate and respiratory rate, in patients receiving ventilatory assistance. Wong et 
$\mathrm{al}^{32}$ studied the effects of music therapy on anxiety in ventilator-dependent patients. Findings indicated that music therapy was more effective in decreasing state anxiety than was an uninterrupted rest period. However,blood pressure and respiratory rate showed no significant differences in the 2 conditions over time. A randomized controlled tria ${ }^{33}$ indicated that patients on mechanical ventilation who listened to a single 30-minute session of music appeared to show greater relaxation as manifested by a decrease in physiological indices and an increase in comfortable resting behaviours. Recently, Han et al34 confirmed that short-term therapeutic effects of music listening results in substantial reduction in physiological stress responses arising from anxiety, in mechanically ventilated patients.

\section{Clinical procedures}

Colt et $\mathrm{al}^{35}$ observed that relaxation music administered through headphones to patients during flexible bronchoscopy does not decrease procedure-related state anxiety. Kotwal et a ${ }^{36}$ demonstrated that the background Indian classical music is efficacious in reducing psychological distress during a gastroscopic examination. Smolen et $\mathrm{al}^{37}$ examined the effects of music therapy on selfreported and physiological signs of anxiety among ambulatory patients undergoing colonoscopy. Their findings indicate that music therapy has the potential to reduce physiological indicators of anxiety and the need for sedation among individuals undergoing a colonoscopy. Listening to music during ambulatory colonoscopies decreases the level of anxiety that is inherent to the process without other anxiolytic methods ${ }^{38}$.

Studies on the anxiolytic effects of music in the context of cardiac catheterization have yielded mixed results. Hamel ${ }^{39}$ observed that patients waiting for their cardiac catheterization benefit from music therapy. Anxiety and the heightened physiological values elicited by the stress response are reduced. In contrast, Taylor-Piliae and Chair ${ }^{40}$ demonstrated that the use of music therapy or sensory information did not significantly reduce anxiety, improve mood state, decrease heart or respiratory rate among subjects undergoing cardiac catheterization. Music therapy results in a statistically significant reduction in anxiety scores in patients undergoing angiography procedures. ${ }^{41-43}$

\section{Obstetrics \& Gynaecology}

A randomized controlled study ${ }^{44}$ has demonstrated that exposure to music resulted in significantly less pain and lower anxiety during colposcopy examination. A controlled trial by Chang et al ${ }^{45}$ provides evidence that two-week music therapy during pregnancy provides quantifiable psychological benefits. Carefully selected music that incorporates a patient's own preferences may offer an inexpensive and effective method to reduce anxiety for antepartum women with high risk pregnancies who have been prescribed bedrest. ${ }^{46} \mathrm{~A}$ recent randomized controlled tria ${ }^{47}$ provides good evidence for the use of music as an empirically based intervention of women for labour pain and anxiety during the latent phase of labour.

Music therapy can reduce anxiety and create a more satisfying experience for women undergoing caesarean delivery. ${ }^{48}$ Postoperative use of patientselected music in caesarean section surgery alleviates pain and reduces the need for other analgesics, thus improving the recovery and early contact of mothers with their children. ${ }^{49} \mathrm{~A}$ recent study by Tseng et $a^{50}$ does not provide evidence that preselected designer music reduced stress and anxiety levels among postpartum women.

\section{Dementia}

Results of studies on the impact of music on patients with dementia are controversial. According to Sung et $\mathrm{al}^{51}$, preferred music listening has a positive impact by reducing the level of anxiety in older adults with dementia. In contrast, Cooke et $\mathrm{a}^{52}$ have demonstrated that music does not significantly affect agitation and anxiety in older people with dementia.

\section{Dental procedures}

Soothing music reduces anxiety in patients undergoing root canal treatment..$^{53}$ Newton $^{54}$ demonstrated that relaxing music administered through headphones to subjects during root canal treatment decreased the procedure-related anxiety of the patients, but does not significantly 
affect blood pressure and heart rate over the procedure.

\section{Miscellaneous scenarios}

Music has been shown to be effective in reducing anxiety and dyspnoea along with physiologic measures such as systolic $\mathrm{BP}$, pulse rate and respiratory rate in COPD patients hospitalized with exacerbation. ${ }^{14}$ Guetin et a ${ }^{55}$ confirmed the usefulness of music therapy in the treatment of anxiety-depression and mood in patients with traumatic brain injury.

The role of music as a therapeutic intervention for anxiety in patients receiving radiation therapy was studied by Smith et al. ${ }^{56}$ No significant difference existed between the music group and control groups to suggest that music moderated the level of anxiety during radiotherapy. However, post-hoc analyses identified changes and trends in state anxiety scores, suggesting a possible benefit of music therapy during radiotherapy. Yilmaz et $\mathrm{a}^{17}$ have demonstrated that music decreases anxiety and provides sedation in patients undergoing extracorporeal shock wave lithotripsy. Ferrer ${ }^{58}$ investigated the effects of familiar music on the anxiety levels of patients undergoing chemotherapy treatment. Results of the study showed statistically significant improvement for the experimental group on the measures of anxiety, fear, fatigue, relaxation, and diastolic blood pressure. No significant differences between groups were found for heart rate and systolic blood pressure. Shabanloei et al ${ }^{59}$ demonstrated positive effects of music therapy on pain and anxiety in patients undergoing bone marrow biopsy and aspiration. Music therapy significantly decreases the acute procedural pain, anxiety, and muscle tension levels associated with daily burn dressing changes. ${ }^{60}$ Music can improve depression, anxiety, and relationships in psychiatric patients. ${ }^{61}$

\section{Clinical implicationhs of anxiety, elevated heart rate and blood preshsure}

Evidence suggests that people with anxiety disorders are at greater risk for developing a number of chronic medical conditions. ${ }^{62}$ Anxiety has now been implicated in several chronic physical illnesses, including heart disease, chronic respiratory disorders, and gastrointestinal conditions. ${ }^{62}$

Anxiety can produce disturbances in GI function. ${ }^{3}$ Research indicates an association between high anxiety levels and the development of IBS following a bowel infection. ${ }^{62} \mathrm{~A}$ high level of anxiety symptoms raises the risk of further coronary events in patients after MI by two to five times that for non-anxious comparison patients. 3 High anxiety levels are associated with a tripling of risk of sudden cardiac death. ${ }^{3}$ In asthmatic individuals, high levels of anxiety are associated with increased rates of hospitalization and asthmaassociated mortality. ${ }^{3}$

Elevated resting heart rate is a known, independent cardiovascular risk factor in healthy men and women. ${ }^{63 ; 64}$ Epidemiological studies have reported that a high heart rate is associated with a higher risk of all-cause mortality and cardiovascular events. ${ }^{65}$ Resting heart rate and BP proportionally raise the risk for type- 2 diabetes mellitus. ${ }^{66}$ Blood pressure of young individuals shows a significant association with cardiovascular risk variables and the occurrence of metabolic syndrome in young adult life. ${ }^{67}$ Studies have demonstrated a continuous and graded relationship between 'normal' systolic blood pressure (SBP) and cardiovascular disease. ${ }^{68}$ There is a linear relationship between normotensive SBP and risk of heart failure. ${ }^{68}$

\section{Conclusions}

Music-evoked emotions modulate activity in the limbic system and hypothalamus, and can thus have a profound impact on autonomic and physiological responses. The anxiolytic effect of music in various clinical scenarios has been documented by several researchers. However, results are inconsistent across studies. Some studies on the anxiolytic effect of music in clinical settings have indicated dissociation between changes in the psychological and peripheral correlates of anxiety in response to music.Research on the impact of music on physiological processes in healthy individuals is not as abundant as research data on the therapeutic effects on music in the context of illness. Research on the role of music in disease prevention, health 
promotion, and positive psychology is meagre. There is a definite shortage of published Indian research on the physiological effects of music. There are a number of individual and sociocultural factors that influence responses to music. Existing research data pertaining to the impact of music on health needs to be systematically replicated in the Indian context.

\section{Recommendations for research}

Rigorous randomized controlled trials need to be conducted on large samples to clarify and establish the role of music in disease prevention, health promotion, and positive psychology, in the Indian context.Existing research data pertaining to the therapeutic role of music in various clinical settings needs to be systematically replicated in Indian subjects, through randomized controlled trials.Prospective, controlled, follow-up studies are essential to test the long-term impact of music on health.Controlled trials are needed to compare the therapeutic efficacy of patient-preferred music with researcher-selected music.Future research on music therapy needs to specifically address issues such as music preference of the subjects, subjects' personal associations with the music, musical background ("musicality") of the subjects, and sociocultural variables. Studies on the anxiolytic or stress-relieving effects of music should routinely include objective biochemical measures of stressinduced autonomic arousal such as neuroendocrine variables.Functional neuroimaging studies on the neurophysiology of music need to be reproduced on a larger scale. Such studies would serve to elucidate and establish the neural pathways that mediate the impact of music on health.

\section{References}

1. Sadock BJ, Sadock VA. The brain and behavior. In: Sadock BJ, Sadock VA, eds. Kaplan \& Sadock's synopsis of psychiatry. 10th ed. Philadelphia: Lippincott Williams \& Wilkins; 2009;70-132.

2. World health organization. The world health report 2001 - Mental health: New understanding, new hope. Geneva: World health organization, 2001.

3. Sadock BJ, Sadock VA. Psychosomatic medicine. In: Sadock BJ, Sadock VA, eds. Kaplan \& Sadock's synopsis of psychiatry. 10th ed. Philadelphia: Lippincott Williams \& Wilkins; 2009;813-838.

4. Sadock BJ, Sadock VA. Complementary and alternative medicine in psychiatry. In: Sadock BJ, Sadock VA, eds. Kaplan
\& Sadock's synopsis of psychiatry. 10th ed. Philadelphia: Lippincott Williams \& Wilkins; 2009;839-856.

5. American Music Therapy Association. Music therapy and medicine. American Music Therapy Association [serial online] 2007; Available from: American Music Therapy Association. Accessed September 7, 2007.

6. Bradt J, Dileo C. Music for stress and anxiety reduction in coronary heart disease patients. Cochrane Database Syst Rev 2009;CD006577.

7. Lake JH. Nonconventional approaches in mental health care. In: Sadock BJ, Sadock VA, Ruiz P, eds. Kaplan \& Sadock's comprehensive textbook of psychiatry. 9th ed. Philadelphia: Lippincott Williams \& Wilkins; 2009;2592-2615.

8. Drevets WC, Charney DS, Rauch SL. Neuroimaging and the neuroanatomical circuits implicated in anxiety, fear, and stress-induced circuitry disorders. In: Sadock BJ, Sadock VA, Ruiz P, eds. Kaplan \& Sadock's comprehensive textbook of psychiatry. 9th ed. Philadelphia: Lippincott Williams \& Wilkins; 2009;1881-1898.

9. Melchitzky DS, Lewis DA. Functional neuroanatomy. In: Sadock BJ, Sadock VA, Ruiz P, eds. Kaplan \& Sadock's comprehensive textbook of psychiatry. 9th ed. Philadelphia: Lippincott Williams \& Wilkins; 2009;5-42.

10. Kreibig SD. Autonomic nervous system activity in emotion: A review. BiolPsychol 2010.

11. Sadock BJ, Sadock VA. Anxiety disorders. In: Sadock BJ, Sadock VA, eds. Kaplan \& Sadock's synopsis of psychiatry. 10th ed. Philadelphia: Lippincott Williams \& Wilkins; 2009;579-633.

12. Ganong WF. Cardiovascular regulatory mechanisms. In: Ganong WF, ed. Review of medical physiology. 22nd ed. McGraw-Hill; 2005;597-610.

13. Grillon C, Cornwell BR. Anxiety disorders: Psychophysiological aspects. In: Sadock BJ, Sadock VA, Ruiz P, eds. Kaplan \& Sadock's comprehensive textbook of psychiatry. 9th ed. Philadelphia: Lippincott Williams \& Wilkins; 2009;1864-1871.

14. Singh VP, Rao V,Prem V,Sahoo RC, KeshavPai K. Comparison of the effectiveness of music and progressive muscle relaxation for anxiety in COPD--A randomized controlled pilot study. ChronRespir Dis 2009;6:209-216.

15. Koelsch S. Towards a neural basis of music-evoked emotions. Trends CognSci 2010;14:131-137.

16. Koelsch S. Investigating emotion with music: neuroscientific approaches. Ann N Y AcadSci 2005;1060:412-418.

17. Menon V, Levitin DJ. The rewards of music listening: response and physiological connectivity of the mesolimbic system. Neuroimage 2005;28:175-184.

18. Knight WE, Rickard NS. Relaxing music prevents stressinduced increases in subjective anxiety, systolic blood pressure, and heart rate in healthy males and females. J Music Ther 2001;38:254-272.

19. Miller M, Mangano CC, Beach V, Kop WJ, Vogel RA. Divergent effects of joyful and anxiety-provoking music on endothelial vasoreactivity. Psychosom Med 2010;72:354-356.

20. White JM. Music therapy: an intervention to reduce anxiety in the myocardial infarction patient. Clin Nurse Spec 1992;6:58-63. 
21. Elliott D. The effects of music and muscle relaxation on patient anxiety in a coronary care unit. Heart Lung 1994;23:27-35.

22. Barnason S, Zimmerman L, Nieveen J. The effects of music interventions on anxiety in the patient after coronary artery bypass grafting. Heart Lung 1995;24:124-132.

23. Winter MJ, Paskin S, Baker T.Music reduces stress and anxiety of patients in the surgical holding area. J Post AnesthNurs 1994;9:340-343.

24. Augustin P, Hains AA. Effect of music on ambulatory surgery patients' preoperative anxiety. AORN J 1996;63:750, 753-750, 758.

25. Haun M, Mainous RO, Looney SW. Effect of music on anxiety of women awaiting breast biopsy. Behav Med 2001;27:127132.

26. Wang SM, Kulkarni L, Dolev J, Kain ZN. Music and preoperative anxiety: a randomized, controlled study. AnesthAnalg 2002;94:1489-94, table.

27. Cooke M, Chaboyer W, Schluter P, Hiratos M. The effect of music on preoperative anxiety in day surgery. J AdvNurs 2005;52:47-55.

28. Mok E, Wong KY. Effects of music on patient anxiety. AORN J 2003;77:396-6, 409.

29. Allred KD, Byers JF, Sole ML. The effect of music on postoperative pain and anxiety. Pain ManagNurs 2010;11:1525.

30. Nilsson U. The anxiety- and pain-reducing effects of music interventions: a systematic review. AORN J 2008;87:780-807.

31. Chlan L. Effectiveness of a music therapy intervention on relaxation and anxiety for patients receiving ventilatory assistance. Heart Lung 1998;27:169-176.

32. Wong HL, Lopez-Nahas V, Molassiotis A. Effects of music therapy on anxiety in ventilator-dependent patients. Heart Lung 2001;30:376-387.

33. Lee OK, Chung YF, Chan MF, Chan WM. Music and its effect on the physiological responses and anxiety levels of patients receiving mechanical ventilation: a pilot study. J Clin Nurs 2005;14:609-620.

34. Han L, Li JP, Sit JW, Chung L, Jiao ZY, Ma WG. Effects of music intervention on physiological stress response and anxiety level of mechanically ventilated patients in China: a randomised controlled trial. J Clin Nurs 2010;19:978-987.

35. Colt HG, Powers A, Shanks TG. Effect of music on state anxiety scores in patients undergoing fiberoptic bronchoscopy. Chest 1999;116:819-824.

36. Kotwal MR, Rinchhen CZ, Ringe VV. Stress reduction through listening to Indian classical music during gastroscopy. DiagnTherEndosc 1998;4:191-197.

37. Smolen D, Topp R, Singer L. The effect of self-selected music during colonoscopy on anxiety, heart rate, and blood pressure. ApplNurs Res 2002;15:126-136.

38. Lopez-CeperoAndrada JM, Amaya VA, Castro AguilarTablada $\mathrm{T}$ et al. Anxiety during the performance of colonoscopies: modification using music therapy. Eur J GastroenterolHepatol 2004;16:1381-1386.

39. Hamel WJ. The effects of music intervention on anxiety in the patient waiting for cardiac catheterization. Intensive Crit Care Nurs 2001;17:279-285.
40. Taylor-Piliae RE, Chair SY.The effect of nursing interventions utilizing music therapy or sensory information on Chinese patients' anxiety prior to cardiac catheterization: a pilot study. Eur J CardiovascNurs 2002;1:203-211.

41. Buffum MD, Sasso C, Sands LP, Lanier E, Yellen M, Hayes A. A music intervention to reduce anxiety before vascular angiography procedures. J VascNurs 2006;24:68-73.

42. Moradipanah F, Mohammadi E, Mohammadil AZ. Effect of music on anxiety, stress, and depression levels in patients undergoing coronary angiography. East Mediterr Health J 2009;15:639-647.

43. Weeks BP, Nilsson U. Music interventions in patients during coronary angiographic procedures: A randomized controlled study of the effect on patients' anxiety and well-being. Eur J CardiovascNurs 2010.

44. Chan YM, Lee PW, Ng TY, Ngan HY, Wong LC. The use of music to reduce anxiety for patients undergoing colposcopy: a randomized trial. GynecolOncol 2003;91:213-217.

45. Chang MY, Chen $\mathrm{CH}$, Huang KF. Effects of music therapy on psychological health of women during pregnancy. J Clin Nurs 2008;17:2580-2587.

46. Yang M, Li L, Zhu $\mathrm{H}$ et al. Music therapy to relieve anxiety in pregnant women on bedrest: a randomized, controlled trial. MCN Am J Matern Child Nurs 2009;34:316-323.

47. Liu YH, Chang MY, Chen CH. Effects of music therapy on labour pain and anxiety in Taiwanese first-time mothers. J Clin Nurs 2010;19:1065-1072.

48. Chang SC, Chen CH. Effects of music therapy on women's physiologic measures, anxiety, and satisfaction during cesarean delivery. Res Nurs Health 2005;28:453-461.

49. Ebneshahidi A, Mohseni M. The effect of patient-selected music on early postoperative pain, anxiety, and hemodynamic profile in cesarean section surgery. J Altern Complement Med 2008;14:827-831.

50. Tseng YF, Chen CH, Lee CS. Effects of listening to music on postpartum stress and anxiety levels. J Clin Nurs 2010;19:1049-1055.

51. Sung HC, Chang AM, Lee WL. A preferred music listening intervention to reduce anxiety in older adults with dementia in nursing homes. J Clin Nurs 2010;19:1056-1064.

52. Cooke ML, Moyle W, Shum DH, Harrison SD, Murfield JE. A randomized controlled trial exploring the effect of music on agitated behaviours and anxiety in older people with dementia. Aging Ment Health 2010;1-12.

53. Lai HL, Hwang MJ, Chen CJ, Chang KF, Peng TC, Chang FM. Randomised controlled trial of music on state anxiety and physiological indices in patients undergoing root canal treatment. J Clin Nurs 2008;17:2654-2660.

54. Newton JT. Music may reduce anxiety during invasive procedures in adolescents and adults. Evid Based Dent 2009;10:15.

55. Guetin S, Soua B, Voiriot G, Picot MC, Herisson C. The effect of music therapy on mood and anxiety-depression: an observational study in institutionalised patients with traumatic brain injury. Ann PhysRehabil Med 2009;52:30-40.

56. Smith M, Casey L, Johnson D, Gwede C, Riggin OZ. Music as a therapeutic intervention for anxiety in patients receiving radiation therapy. OncolNurs Forum 2001;28:855-862. 
57. Yilmaz E, Ozcan S, Basar M, Basar H, Batislam E, Ferhat M. Music decreases anxiety and provides sedation in extracorporeal shock wave lithotripsy. Urology 2003;61:282-286.

58. Ferrer AJ. The effect of live music on decreasing anxiety in patients undergoing chemotherapy treatment. J Music Ther 2007;44:242-255.

59. Shabanloei R, Golchin M, Esfahani A, Dolatkhah R, Rasoulian M. Effects of music therapy on pain and anxiety in patients undergoing bone marrow biopsy and aspiration. AORN J 2010;91:746-751.

60. Tan X, Yowler CJ, Super DM, Fratianne RB. The efficacy of music therapy protocols for decreasing pain, anxiety, and muscle tension levels during burn dressing changes: a prospective randomized crossover trial. J Burn Care Res 2010;31:590-597.

61. Choi A-N, Lee MS, Lim H-J. Effects of group music intervention on depression, anxiety, and relationships in psychiatric patients: a pilot study. J Altern Complement Med. 2008 Jun;14(5):567-70.

62. Harvard University. Anxiety and physical illness. Harvard Health Publications [serial online] 2010; Available from: Harvard Health Publications. Accessed August 15, 2010.
63. Cooney MT, Vartiainen E, Laatikainen T, Joulevi A, Dudina A, Graham I. Simplifying cardiovascular risk estimation using resting heart rate. Eur Heart J 2010.

64. Cooney MT, Vartiainen E, Laatikainen T, Juolevi A, Dudina A, Graham IM. Elevated resting heart rate is an independent risk factor for cardiovascular disease in healthy men and women. Am Heart J 2010;159:612-619.

65. Perret-Guillaume C, Joly L, Benetos A. Heart rate as a risk factor for cardiovascular disease. ProgCardiovasc Dis 2009;52:6-10.

66. Nagaya T, Yoshida H, Takahashi H, Kawai M. Resting heart rate and blood pressure, independent of each other, proportionally raise the risk for type- 2 diabetes mellitus. Int J Epidemiol 2010;39:215-222.

67. Campana EM, Brandao AA, Pozzan R et al. Blood pressure in young individuals as a cardiovascular risk marker. The Rio de Janeiro study. Arq Bras Cardiol 2009;93:608-665.

68. Britton KA, Gaziano JM, Djousse L. Normal systolic blood pressure and risk of heart failure in US male physicians. Eur J Heart Fail 2009;11:1129-1134. 